\title{
PENTINGNYA LINGKUNGAN DALAM PEMBELAJARAN BAHASA INDONESIA
}

\author{
Oleh : Marzulianis / 19016102 \\ marzulianisaya@gmail.com
}

Masalah lingkungan bukanlah suatu hal yang baru. Persoalan mengenai lingkungan seperti pembakaran hutan, pencemaran lingkungan, pemburuan hewan serta tumbuhan yang dilindungi adalah permasalahan yang dari dulunya sudah ada, dan terus berlanjut tanpa terdapat penyelesaian. Persoalan lingkungan ini ditimbulkan oleh kegiatan manusia yang ceroboh dan intensif pada wilayah alami untuk meningkatkan kualitas hidup mereka. Kerusakan lingkungan mengakibatkan serangkaian persoalan dengan alam sumber daya, iklim, polusi, makanan, dan ekonomi, sebagai akibat ulah tangan dari manusia terjadi ketidakseimbangan pada lingkungan hidup.

Mitsuki dan Lai (pada Ramadhan et al, 2019), menyatakan bahwa semua orang di seluruh dunia sedang menghadapi persoalan lingkungan yang membahayakan kehidupan, dampak pemanasan global, hujan asam, perusakan lapisan ozon, pencemaran lingkungan, kerusakan alam, serta berkurangnya keanekaragaman hayati yang sangat berpengaruh bagi kehidupan generasi sekarang dan generasi masa yang akan datang. Permasalahan lingkungan yang seringkali terjadi yaitu persoalan kebersihan, karena kurangnya rasa peduli warga terhadap lingkungan sekitar. Menjaga kebersihan ialah kewajiban bagi setiap individu, selain sebagai anugerah yang diberikan sang pencipta pada hamba-Nya, kesehatan lingkungan wajib tetap dijaga supaya terhindar dari berbagai macam penyakit.

Salah satu upaya penyelesaian masalah lingkungan yang berkelanjutan ini ialah dengan menanamkan semenjak dini pada generasi muda tentang pentingnya menjaga lingkungan. Hal-hal kecil seperti tidak membuang sampah pada tempatnya, memakai air seperlunya ialah langkah awal yang mampu dilakukan. Menanamkan rasa tanggung jawab dan kesadaran akan menjaga lingkungan dapat dilakukan pada sekolah dengan menerapkan materi lingkungan pada pembelajaran. Salah satu pembelajaran yang bisa dikaitkan dengan materi lingkungan ialah pembelajaran bahasa. Ramadhan et al (2018) mengungkapkan contoh pembelajaran yang inovatif bisa meningkatkan hasil belajar 
siswa. Maka dari itu, pengintegrasian pendidikan lingkungan pada proses pembelajaran bahasa Indonesia ialah salah satu cara dalam mewujudkan dan mengembangkan kemampuan peserta didik sehingga peserta didik bisa berinovasi dan berkolaborasi menggunakan lingkungan yang ada disekitar mereka. Sejalan dengan itu, Ramadhan et al (2019) menyatakan lembaga pendidikan menjadi pemangku kepentingan utama wajib menaikkan kesadaran lingkungan peserta didik. oleh karena itu, pendidikan berbasis lingkungan bisa diterapkan pada mata pelajaran lain, seperti mata pelajaran bahasa Indonesia. Uyar dan Ensar (dalam Ramadhan et al, 2019) berpendapat bahwa menggunakan tema lingkungan dalam pembelajaran teks dapat memicu minat siswa dalam mempelajari bahasa dan secara berimplikasi dapat meningkatkan pengetahuan siswa tentang lingkungan hidup. Putri dan Syahrul (2019) mengatakan bahwa pada pembelajaran di lingkungan sekolah, pengajaran membaca wajib memperoleh perhatian yang berfokus dari pendidik di Indonesia. Melalui pengajaran, pendidik mampu mengarahkan siswa pada pembelajaran bahasa.

Menurut Sukma (2017) kemampuan berliterasi mempunyai efek yang signifikan terhadap keberhasilan peserta didik pada belajar dan kehidupan sehari-hari. Melalui keterampilan literasi yang baik, akan membantu peserta didik dalam memahami teks lisan, tulisan, serta teks visual. Sejalan dengan itu, Sukma (2019) mengatakan pengajar hendaknya menyampaikan motivasi pada peserta didik. Melalui motivasi tadi seorang pengajar bisa membentuk berbagai pengalaman belajar bagi peserta didik. Indriyani et.al (2019) mengungkapkan literasi peserta didik perlu ditingkatkan terutama literasi baca tulis. kemudian, juga perlu mengetahui bagaimana pelaksanaan literasi yang sudah dilaksanakan pada sekolah. Sukma (2020) mengungkapkan penanaman karakter penting ditanamkan semenjak peserta didik masih duduk dibangku sekolah dasar. Penanaman karakter bisa dilakukan dalam proses pembelajaran di sekolah. Banyaknya keragaman karakter dan norma peserta didik di sekolah berasal dari latar belakang keluarga yang tidak sama ialah dampak besar sehingga mengakibatkan hal-hal buruk dari karakter anak yang buruk. Zulhafizh et al (2013) menyatakan bahwa perilaku serta motivasi belajar peserta didik berkontribusi dengan hasil belajarnya, yakni bahasa Indonesia. Munandar (pada Piliang et al, 2014) menyatakan bahwa kreativitas ialah hasil 
hubungan individu menggunakan lingkungannya, maka tampak kentara bahwa kreativitas individu sangat dipengaruhi oleh dorongan atau motivasi dari dalam diri dan lingkungannya. Hal-hal yang sudah disebutkan sebelum ini nantinya akan bekerjasama dan berpengaruh terhadap akibat belajar peserta didik.

Menurut Obasoro, Oyinloye, dan Ilensami (dalam Ramadhan et al, 2019) siswa perlu memiliki pengalaman dalam mengambil inisiatif sehubungan dengan persyaratan yang mendesak di bidang tantangan global dan masyarakat. Sejalan dengan itu, Bergman B,G (dalam Ramadhan et al, 2019) mengungkapkan bahwa guru memainkan peran penting dalam mengajarkan pendidikan lingkungan hidup. Guru dapat memberikan materi lingkungan kepada siswa agar siswa dapat memahami contoh yang tepat yang bisa ditemui di sekitarnya. Selain guru, siswa juga memiliki peranan yang penting dalam proses pembelajaran. Karena tanpa adanya respon atau tindakan pengaplikasian materi yang diberikan oleh guru, maka tujuan dari pembelajaran tersebut tidak akan tercapai. Hal ini sesuai dengan pernyataan Sukma (2012) dan Ramadhan et al (2019) bahwa guru berfungsi sebagai fasilitator dan manajer pembelajaran dalam proses pembelajaran.

Berdasarkan permasalahan yang telah dibahas di atas, penulis melakukan penelitian mengenai pentingnya lingkungan dalam pembelajaran bahasa Indonesia dengan cara membuat 10 pernyataan dengan angket google form. Hasil yang didapatkan adalah sebagai berikut. Pernyataan pertama, dalam pelajaran bahasa Indonesia materi tentang lingkungan harus diterapkan sejak dini, sangat setuju $37,5 \%$, setuju $62,5 \%$. Pernyataan kedua, menggunakan materi lingkungan dalam pembelajaran bahasa Indonesia, guru dapat menumbuhkan rasa cinta lingkungan pada diri siswa, sangat setuju $46,9 \%$, setuju $53,1 \%$. Pernyataan ketiga, membuat puisi dengan mengamati lingkungan, sangat setuju $31,3 \%$, setuju 68,8\%. Pernyataan keempat, lingkungan sangat berpengaruh terhadap proses pembelajaran bahasa Indonesia, sangat setuju $28,1 \%$, setuju $68,8 \%$, kurang setuju $6,3 \%$. Pernyataan kelima, lingkungan yang bersih adalah salah satu penunjang agar terlaksana pembelajaran yang baik, sangat setuju $53,1 \%$, setuju $46,9 \%$. Pernyataan keenam, lingkungan dapat dijadikan sebagai sumber pembelajaran bahasa Indonesia, sangat setuju $18,8 \%$, setuju $68,8 \%$, 
kurang setuju 9,4\%, tidak setuju 3,1\%. Pernyataan ketujuh, legenda Danau Toba berkaitan dengan lingkungan dalam pembelajaran bahasa indonesia, sangat setuju $25 \%$, setuju $71,9 \%$, kurang setuju $3,1 \%$. Pernyataan kedelapan, kurikulum pembelajaran bahasa Indonesia harus dijadikan materi lingkungan sebagai salah satu tujuan pembelajaran, sangat setuju $15,6 \%$, setuju $81,3 \%$, kurang setuju $3,1 \%$. Pernyataan ke sembilan, teks Narasi dengan tema lingkungan dalam pembelajaran Bahasa Indonesia, sangat setuju $25 \%$, setuju $71,9 \%$, kurang setuju 3,1\%. Pernyataan kesepuluh, mengambil objek yang unik dalam lingkungan pada pembuatan dongeng, sangat setuju $40,6 \%$, setuju $56,3 \%$, kurang setuju $3,1 \%$.

Dari hasil penelitian di atas, bisa disimpulkan bahwa materi lingkungan sangat penting untuk diterapkan dalam pembelajaran bahasa Indonesia. Materi lingkungan dapat memudahkan siswa dalam memamahami materi bahasa Indonesia dengan baik. Materi lingkungan merupakan materi yang sangat erat kaitannya dengan kehidupan sehari-hari. Hal ini sesuai dengan pendapat Hauchild S, Poltavthenko E, dan Stoller F, L (dalam Ramadhan et al, 2019) bahwa dengan mengintegrasikan pendidikan lingkungan ke dalam kelas, guru dapat meningkatkan minat siswa terhadap permasalahan kontemporer yang mungkin langsung mempengaruhi masa depan mereka. 


\section{REFERENSI}

Piliang, Wilda S. H., Atmazaki, dan Syahrul Ramadhan. (2014). Kontribusi Kemampuan Apresiasi Sastra dan Berpikir Kreatif terhadap Keterampilan Bermain Drama pada Siswa Kelas XII IPS SMA Negeri 2 Rengat Kabupaten Indragiri Hulu. Jurnal Bahasa, Sastra dan Pembelajaran, 2(2), 75-87.

Zulhafizh, Atmazaki, dan Syahrul Ramadhan. (2013). Kontribusi Sikap dan Motivasi Belajar Siswa terhadap Hasil Belajar Bahasa Indonesia. Jurnal Bahasa, Sastra dan Pembelajaran, Volume 1, Nomor 2, Halaman 13-28.

Putri, Diana dan Syahrul R. (2019). Korelasi Keterampilan Membaca Pemahaman dan Keterampilan Menulis Teks Laporan Hasil Observasi Siswa Kelas VII SMP Negeri 4 Pariaman. Jurnal Pendidikan Bahasa dan Sastra Indonesia, 8(1), seri A 62-69.

Ramadhan, S., Elfia Sukma, dan Vivi Indriyani. (2019). Environmental Education and Disaster Mitigation Through Language Learning. IOP Conference Series: Earth and Environmental Science, 314, p. 1-9.

Ramadhan, S., Elfia Sukma, dan Vivi Indriyani. (2019). Persepsi Guru terhadap Penggunaan Bahan Ajar Bahasa Indonesia dengan Perangkat Seluler dan Aplikasi Edmodo. Seminar Internasional Riksa Bahasa.

Sukma, Elfia. (2012). Pembelajaran Sastra yang Integratif Berbasis Kompetensi. International Conference on Languages and Arts, Halaman 432-436.

Sukma E, Ritawati M, dan Rizky A. (2017). Literacy Media Development in Improving Reading and Writing Skill of Early Class Students in Elementary School Padang Utara Padang. Advances in Social Science, Education and Humanities Research, Vol 118.

Sukma E. et.al. (2019). Problems in Oral Language Teaching in Primary School. Advances in Social Science. Education and Humanities Research, Volume 301. Sukma E, dan VP Azrianti. (2020). Instilling Positive Characters in Students Using Folker in the Macromedia Application. Advances in Social Science, Education and 
Humanities Research, Volume 485.

Ramadhan, S., Yasnur Asri, dan Vivi Indriyani . (2018). Learning Module Design Writing Argumentative Text Based Problem-Based Learning. Advances in Social Science, Education and Humanities Research, Vol 263: 194-200.

Sukma E, dan VP Azrianti. (2020). Instilling Positive Characters in Students Using Folker in the Macromedia Application. Advances in Social Science, Education and Humanities Research, Volume 485. 